\title{
A Phase 3, Randomized Double-Blind Study of the Efficacy and Safety of Low-Dose SHP465 Mixed Amphetamine Salts Extended-Release in Children with Attention-Deficit/Hyperactivity Disorder
}

\author{
Greg Mattingly, MD, ${ }^{1}$ Valerie Arnold, MD, ${ }^{2}$ Brian Yan, $\mathrm{PhD},{ }^{3}$ Ming Yu, MD, $\mathrm{PhD},{ }^{4}$ and Brigitte Robertson, $\mathrm{MD}^{4, *}$
}

\begin{abstract}
Objectives: In a previous pivotal study of children and adolescents (aged 6-17 years) with attention-deficit/hyperactivity disorder (ADHD), dose-optimized SHP465 mixed amphetamine salts (MAS) extended-release (12.5-25 mg once daily) was superior to placebo in reducing ADHD symptoms. This study evaluated the efficacy, tolerability, and safety of $6.25 \mathrm{mg}$ SHP465 MAS once daily (one-half the lowest approved dose for adolescents and adults) versus placebo in children aged 6-12 years with ADHD.

Methods: Children (aged 6-12 years) with Diagnostic and Statistical Manual of Mental Disorders, Fifth edition-defined ADHD; baseline ADHD-Rating Scale, Fifth Edition, Child, Home Version total scores (ADHD-RS-5-HV-TS) $\geq 28$; and baseline Clinical Global Impressions-Severity scores $\geq 4$ were eligible. Participants received 6.25 mg SHP465 MAS once daily or placebo for 4 weeks. The primary (ADHD-RS-5-HV-TS change from baseline at week 4) and key secondary (Clinical Global Impressions-Improvement [CGI-I] score at week 4) efficacy end points were assessed using linear mixed-effects models for repeated measures. Safety and tolerability assessments included treatment-emergent adverse events (TEAEs) and vital sign changes.

Results: Of 89 randomized participants, 83 completed the study (placebo, $n=41$; SHP465 MAS, $n=42$ ). At week 4, the least squares mean (95\% confidence interval) treatment differences (SHP465 MAS-placebo) were not statistically significant for ADHD-RS-5-HV-TS change ( -1.9 [ -6.8 to 3.1], $p=0.451$; effect size $[\mathrm{ES}]=0.17)$ or CGI-I score $(-0.1$ [ -0.5 to 0.3 , nominal $p=0.597 ; \mathrm{ES}=0.12$ ). The percentage of participants reporting TEAEs was $16.3 \%$ with placebo and $24.4 \%$ with SHP465 MAS. The most frequently reported TEAEs (placebo; SHP465 MAS) were headache (7.0\%; 4.4\%) and decreased appetite $(4.7 \% ; 2.2 \%)$. Minimal increases in blood pressure were observed with SHP465 MAS at the final ontreatment assessment.

Conclusions: SHP465 MAS $6.25 \mathrm{mg}$ once daily (one-half the lowest dose approved for adolescents and adults) was well tolerated in children aged 6-12 years but was not superior to placebo in reducing ADHD symptoms, suggesting that this dose of SHP465 MAS was subtherapeutic in this age group. The Clinical Trial Registration number: NCT03325881.
\end{abstract}

Keywords: attention-deficit/hyperactivity disorder (ADHD), children, SHP465 (Mydayis) mixed amphetamine salts, efficacy, safety and tolerability

\footnotetext{
${ }^{1}$ Midwest Research Group, St. Charles, Missouri, USA.

${ }^{2}$ CNS Healthcare, Memphis, Tennessee, USA.

${ }^{3}$ Biostatistics, Shire, a Member of the Takeda Group of Companies, Lexington, Massachusetts, USA.

${ }^{4}$ Global Clinical Development, Shire, a Member of the Takeda Group of Companies, Lexington, Massachusetts, USA.

*At the time this research was conducted; currently employed by Yumanity Therapeutics, Inc., Cambridge, Massachusetts, USA.

Prior presentation: These data were presented at the 2019 meeting of the American Academy of Child and Adolescent Psychiatry (October 14-19, 2019; Chicago, IL).

Funding: This clinical research was funded by Shire Development LLC, a member of the Takeda group of companies, Lexington, MA. Shire Development LLC, a member of the Takeda group of companies, also provided funding to ICON plc (North Wales, PA) for support in writing and editing this article.

(c) Greg Mattingly et al. 2020; Published by Mary Ann Liebert, Inc. This Open Access article is distributed under the terms of the Creative Commons Attribution Noncommercial License (http://creativecommons.org/licenses/by-nc/4.0/) which permits any noncommercial use, distribution, and reproduction in any medium, provided the original author(s) and the source are cited.
} 


\section{Introduction}

$\mathbf{S}^{\mathrm{r}}$ PP465 MIXED AMPHETAMINE salts (MAS) extended-release is a once-daily, single-entity MAS product approved in the United States for the treatment of attention-deficit/hyperactivity disorder (ADHD) in patients aged $\geq 13$ years (Mydayis ${ }^{\circledR} 2019$ ). SHP465 MAS capsules contain three types of drug-releasing beads: an immediate-release bead and two different types of delayed-release beads. Each SHP465 MAS capsule contains equal amounts (by weight) of dextroamphetamine sulfate, amphetamine sulfate, dextroamphetamine saccharate, and amphetamine aspartate monohydrate. This results in a 3:1 ratio of dextroamphetamine to levoamphetamine (D- to L-amphetamine) base equivalent (Mydayis ${ }^{\circledR}$ 2019). In simulated workplace studies in adults and an analog laboratory classroom study in children and adolescents (Wigal et al. 2018a, 2018b, 2019), SHP465 MAS exhibited an onset of efficacy of 2 hours postdose or 4 hours postdose (the first or second postdose assessments) and a duration of efficacy of up to 16 hours postdose (the final postdose assessment) compared with placebo.

Based on phase 3 studies in adults (Spencer et al. 2008; Weisler et al. 2017; Frick et al. 2020) and in children and adolescents (Brams et al. 2018), the recommended starting dose of SHP465 MAS is $12.5 \mathrm{mg}$ once daily, and the maximum doses approved by the U.S. Food and Drug Administration (FDA) are $25 \mathrm{mg}$ once daily in adolescents aged 13-17 years and $50 \mathrm{mg}$ once daily in adults (Mydayis ${ }^{\circledR}$ 2019). In a pivotal study in children and adolescents diagnosed with ADHD referred to above (Brams et al. 2018), dose-optimized SHP465 MAS (12.5$25 \mathrm{mg}$ once daily) were statistically superior to placebo in reducing ADHD-Rating Scale, Fourth Edition (ADHD-RS-IV) total score (effect size [ES], 0.80) and Clinical Global Impressions-Improvement (CGI-I) scale score (ES, 0.65) after 4 weeks of treatment, with $24.2 \%$ of participants having an optimal dose of $12.5 \mathrm{mg}$ SHP465 MAS.

In the same study, the frequency of treatment-emergent adverse events (TEAEs) was greater with SHP465 MAS than placebo, and mean increases in pulse and blood pressure at the final on-treatment assessment (FoTA) were greater with SHP465 MAS than placebo (Brams et al. 2018). These findings are generally consistent with studies of SHP465 MAS in adults (Spencer et al. 2008; Weisler et al. 2017; Frick et al. 2020) and with studies of other amphetamine-based stimulants in children and adolescents with ADHD (Biederman et al. 2002, 2007; Spencer et al. 2006; Findling et al. 2011; Stein et al. 2011).

To assess the efficacy and risk benefit of SHP465 MAS in 6- to 12-year-old children at a lower dose than is currently approved by the U.S. FDA for the treatment of ADHD and to explore the pharmacokinetics, safety, and tolerability of SHP465 MAS in 4- to 5-year-old children, three supporting studies for SHP465 MAS (NCT03327402, NCT03325894, NCT03325881) were conducted. These studies fulfilled both the U.S. FDA Pediatric Research Equity Act (United States Food and Drug Administration 2005) and a pediatric written request from the U.S. FDA.

Study NCT03327402 was a phase 1, safety, tolerability, and pharmacokinetic study of $6.25 \mathrm{mg}$ SHP465 MAS in children aged 4-5 years diagnosed with ADHD. Unpublished data from this study demonstrated that 28 days of $6.25 \mathrm{mg}$ SHP465 MAS once daily resulted in steady-state plasma amphetamine concentration-time profiles after 8 days of exposure, with peak exposure observed at 7.92 hours postdose and concentrations declining monoexponentially thereafter. Once-daily SHP465 MAS were well tolerated in this study, with no serious or severe TEAEs reported (McNamara $\mathrm{N}$ and Ilic K; unpublished data).
Study NCT03325894 was a phase 3, open-label, 12-month safety and tolerability extension study of SHP465 in children aged 4-12 years diagnosed with ADHD. This study, which included participants from the aforementioned pharmacokinetic study, was terminated when results of the pivotal efficacy trial in children and adolescents were not supportive of its continuation.

Study NCT03325881, which is described in this report, was a phase 3 , randomized, double-blind, placebo-controlled 4-week study that evaluated the efficacy, safety, and tolerability of $6.25 \mathrm{mg}$ SHP465 MAS once daily (a dose that is one-half of the lowest dose currently approved for use in patients $\geq 13$ years of age) in children aged 6-12 years diagnosed with ADHD. The data from this study provide important information to clinicians about the efficacy and safety of SHP465 MAS in 6- to 12-year-old children at a dose that is one-half of the lowest dose currently approved for use in adolescents and adults.

\section{Methods}

\section{Study design and treatment}

This phase 3, randomized, double-blind, placebo-controlled fixed-dose study in children aged 6-12 years with ADHD was conducted at 27 sites in the United States between December 9, 2017, and June 7, 2018. It was conducted in compliance with regulations of the FDA Institutional Review Board (IRB) and the International Council for Harmonization Good Clinical Practice guidelines. The protocol, protocol amendments, and informed consent forms were reviewed and approved by the IRB at each institution. Before initiating study-related procedures, written informed consent was obtained from the participant's parent or legally authorized representative (LAR). Documentation of assent was obtained from the participant.

The study consisted of three periods: a 1- to 4-week screening and washout period, a 4-week double-blind treatment period, and a 1-week safety follow-up period. At the start of the double-blind treatment period, participants were randomized $1: 1$ to $6.25 \mathrm{mg}$ SHP465 MAS once daily or placebo. Study medication was taken orally at the same time each day if possible ( $\sim 7$ a.m. \pm 2 hours). The placebo capsules were identical in appearance to the SHP465 MAS capsule to maintain blinding. Randomization to treatment was stratified by age (6-8 and 9-12 years). Interactive web response technology automatically assigned a treatment to each individual.

\section{Participants}

Eligible participants were boys or nonpregnant girls aged 6-12 years meeting primary Diagnostic and Statistical Manual of Mental Disorders, Fifth Edition (DSM-5; American Psychiatric Association 2013) criteria for ADHD based on a detailed psychiatric evaluation using the Mini International Neuropsychiatric Interview version for Children and Adolescents. Participants were also required to have a baseline ADHD-Rating Scale, Fifth Edition, Child, Home Version (ADHD-RS-5-HV) total score $\geq 28$ and baseline Clinical Global Impressions-Severity (CGI-S) of Illness score $\geq 4$. Eligible participants either were not receiving ADHD pharmacotherapy or were not completely satisfied with their current ADHD pharmacotherapy and had been living with the same parent/LAR for $\geq 6$ months.

Key exclusion criteria included having a concurrent chronic or acute illness, disability, or condition that might confound safety assessments, increase participant risk, or prohibit the participant from completing the study; having a controlled or uncontrolled comorbid Axis I or Axis II psychiatric disorder; initiating behavioral therapy within 1 month of baseline; being considered a suicide 
risk, having made a suicide attempt, or having a history of or currently demonstrating suicidal ideation; having a family history of sudden cardiac death or ventricular arrhythmia; having high blood pressure ( $\geq 95$ th percentile for age, sex, and height) at screening and/or baseline; having a history of symptomatic cardiovascular disease or other serious cardiac conditions; having a clinically significant electrocardiogram (ECG) or clinical laboratory abnormalities at screening or baseline; having a height or weight $\leq 5$ th percentile for age and sex at screening or baseline; having an allergy, hypersensitivity, or intolerance to amphetamine; failure to fully respond to an adequate course of amphetamine therapy; and being unable to swallow a pill or administer the contents of a pill in applesauce due to an allergy to applesauce.

\section{Efficacy end points}

The primary efficacy end point was ADHD-RS-5-HV total score change from baseline to week 4. The ADHD-RS-5-HV, which consists of 18 items and includes two 9-item subscales (hyperactivity/impulsivity and inattention), assesses ADHD symptoms in children and adolescents based on home behavior over a 6-month period using DSM-5 diagnostic criteria (DuPaul et al. 2016). Each item is scored on a 4-point scale ( 0 [no problem] to 4 [severe problem]). Total score ranges from 0 to 54 , with higher scores indicating more severe symptoms. The ADHD-RS-5-HV was assessed at baseline and all postbaseline visits through week 4 by the same individual.

The ADHD-RS-5-HV was rated and scored by clinicians based on clinical interviews and responses from parents/LARs. Clinicians were trained, tested, and certified for reliability and consistency by MedAvante-ProPhase (Atlanta, GA). Training included initial qualification of raters, scale-specific didactic and applied learning delivered live at an investigator meeting or online for all raters unable to attend the investigator meeting, and rater certification based on demonstrated scoring and/or administration proficiency.

The key secondary efficacy end point was CGI-I scale score at week 4. The CGI-I (Guy 1976) measures global improvement over time relative to CGI-S score at baseline on a 7-point scale (1 [very much improved] to 7 [very much worse]). The CGI-I was assessed by the same clinician at all postbaseline visits through week 4 .

\section{Safety and tolerability end points}

Safety and tolerability end points included TEAEs, weight and body mass index (BMI), vital signs, ECGs, sleep, and suicidality. TEAEs were defined as adverse events with start dates on or after the first dose of double-blind treatment or start dates before the date of the first dose of double-blind treatment that increased in severity on or after the date of the first dose of double-blind treatment. TEAEs were collected at all study visits from the time of informed consent and were categorized by seriousness, severity, and relatedness to study withdrawal.

Height, weight, and vital sign measurements (systolic blood pressure [SBP], diastolic blood pressure [DBP], and pulse) were assessed at each study visit. Vital sign measurements were taken thrice at 2-minute intervals after a participant had been seated for $\geq 3$ minutes. ECG assessments were conducted at screening, baseline, week 2 , and week 4/early termination after 3 minutes of rest; triplicate assessments were conducted at 3-minute intervals at screening and at baseline if $>32$ days had elapsed since screening.

A parent or LAR used modified versions of the Post Sleep Questionnaire (PSQ) and Children's Sleep Habits Questionnaire (CSHQ) to assess sleep at baseline and all on-treatment visits. The
PSQ (Canafax et al. 2011) assesses sleep quality over the last week by examining time to sleep, sleep latency, the frequency and duration of interrupted sleep, and total sleep time and quality. The CSHQ (Owens et al. 2000) assesses the most common sleep problems in children. Items are rated on a three-point scale ("usually" [5-7 times/week], "sometimes" [2-4 times/week], and "rarely" [0-1 time/week]; some items are scored in reverse) and grouped into eight subscales: bedtime resistance, sleep onset delay, sleep duration, sleep anxiety, night wakings, parasomnias, sleep disordered breathing, and daytime sleepiness. Total sleep disturbance is the sum of all subscale scores minus the scores for the items "needs parent in room to sleep" and "afraid of sleeping alone." Higher scores indicate sleep that is more disturbed.

The Columbia-Suicide Severity Rating Scale (C-SSRS) was used to assess suicide-related thoughts and behaviors (Posner et al. 2011). At screening, the baseline version of the C-SSRS was used. At subsequent on-treatment visits, the "since last visit" version was used.

\section{Data presentation and statistical analyses}

Sample size was determined using nQuery Advisor 7.0 (Statistical Solutions, Ltd., Cork, Ireland). To detect an assumed treatment difference of 11.9 points for ADHD-RS-5-HV total score change from baseline at week 4 (assumed common standard deviation [SD], 14), 26 participants in each treatment arm (52 total participants) needed to complete the study to provide $85 \%$ power for a two-sided $t$ test $(\alpha=0.05)$. Taking into account an expected $15 \%$ dropout rate, 60 participants were targeted for randomization. The statistical assumptions for this sample size calculation correspond to an ES of 0.85 , which is based on a previously published study of children and adolescents treated with 12.5 and $25 \mathrm{mg}$ SHP465 MAS (Brams et al. 2018).

The primary efficacy analysis of ADHD-RS-5-HV total score change from baseline to week 4 was conducted on the full analysis set (all randomized participants receiving $\geq 1$ SHP465 MAS dose and having a baseline and $\geq 1$ postdose ADHD-RS-5-HV total score assessment). The primary analysis used a linear mixed-effects model for repeated measures (MMRM) with treatment, visit, age (6-8 vs. 9-12 years), and the interaction of treatment group with visit as factors. Baseline ADHD-RS-5-HV total score was included as a covariate, and the interaction of baseline ADHD-RS-5-HV total score with visit was adjusted in the model.

The same MMRM analysis used for the primary efficacy analysis was used to assess CGI-I score at week 4 (using CGI-S score as a covariate) and change from baseline at week 4 on the ADHD-RS5-HV hyperactivity/impulsivity and inattention subscales (using the respective subscale scores at baseline as covariates). A separate analysis of the dichotomized CGI-I compared the percentage of participants categorized as improved on the CGI-I (scores of 1 [very much improved] or 2 [much improved]) at week 4 in the full analysis set using a Cochran-Mantel-Haenszel test stratified by age and CGI-S baseline score. Exploratory analyses evaluated changes from baseline to week 4 in ADHD-RS-5-HV total score for each treatment group in participants aged 6-8 years and participants aged $9-12$ years.

A fixed-sequence test procedure was applied across the primary and key secondary efficacy end point analyses. For this procedure, the primary end point was tested first. Secondary efficacy end points were only considered statistically significant if the primary efficacy end point was found to be statistically significant. Statistical significance for both tests was set at a two-sided $p<0.05$. 
Safety and tolerability assessments were conducted in the safety set (randomized participants taking $\geq 1$ dose of study drug). For safety and tolerability end points, the last assessment before the first study drug dose was used as the baseline value. With the exception of adverse events, assessments collected on or 2 days before the last study drug dose were used as postbaseline values. All safety and tolerability data are reported using descriptive statistics.

\section{Results}

\section{Disposition and demographics}

Of 124 screened participants, 89 were randomized (placebo, $n=44$; SHP465 MAS, $n=45$; Fig. 1 ). One participant randomized to placebo was lost to follow-up and did not receive a dose of study drug. Of the 88 participants in the safety set (placebo, $n=43$; SHP465 MAS, $n=45), 87$ were included in the full analysis set (placebo, $n=42$; SHP465 MAS, $n=45$ ) and 83 completed the study (placebo, $n=41$; SHP465 MAS, $n=42$ ). Five randomized participants discontinued (placebo, $n=2$ for lack of efficacy; SHP465 MAS, $n=1$ for protocol violation and $n=2$ for withdrawal by participant or parent/LAR).

In the overall safety set, most participants were boys $(56 / 88$ [63.6\%]) and were white (58/88 [65.9\%]) (Table 1). The mean \pm SD age was $8.8 \pm 2.11$ years, with equal percentages of participants being 6-8 years and 9-12 years of age. The mean \pm SD time since ADHD diagnosis was $1.8 \pm 2.07$ years. The mean \pm SD ADHD-RS5 -HV total score in the overall population was $40.9 \pm 8.40$; most participants were diagnosed as having the combined ADHD subtype $(64 / 88[72.7 \%])$.

\section{Prior and concomitant medication}

Prior use of any medication was reported by $58.1 \%$ (25/43) of the placebo group and 33.3\% (15/45) of the SHP465 MAS group. The ADHD medications used before the study were MAS (placebo, 14.0\% [6/43]; SHP465 MAS, 4.4\% [2/45]), methylphenidate (placebo, 9.3\% [4/43]; SHP465 MAS, 8.9\% [4/45]), amphetamine (placebo, 9.3\% [4/43]; SHP465 MAS, 2.2\% [1/45]), dexamphetamine (placebo, 7.0\% [3/43]; SHP465 MAS, 2.2\% [1/45]), dexmethylphenidate (placebo, 4.7\% [2/43]; SHP465 MAS, 4.4\% [2/45]), lisdexamfetamine dimesylate (placebo, 4.7\% [2/43]; SHP465 MAS, 0), and guanfacine (placebo, 2.3\% [1/43]; SHP465 MAS, $2.2 \%$ [1/45]). Non-ADHD medications used by $>5 \%$ of participants in either treatment group before the study were melatonin (placebo, 7.0\% [3/43]; SHP465 MAS, 4.4\% [2/45]) and ibuprofen (placebo, 7.0\% [3/43]; SHP465 MAS, 2.2\% [1/45]).

The use of concomitant medications during the study was reported by $25.6 \%$ (11/43) of participants in the placebo group and $17.8 \%(8 / 45)$ of participants in the SHP465 MAS group. No single medication was used by $>2$ participants in either treatment group.

\section{Drug exposure and adherence}

The mean \pm SD duration of exposure was $3.9 \pm 0.60$ and $3.9 \pm 0.52$ weeks in the placebo and SHP465 MAS groups, respectively. In the SHP465 MAS group, the mean \pm SD average daily dose was $6.169 \pm 0.2646 \mathrm{mg} /$ day. The mean \pm SD adherence rate ([capsules taken/capsules expected to be taken based on pill counts $] \times 100$ ) during the treatment period was $97.9 \% \pm 5.09 \%$ in the placebo group and $98.2 \% \pm 3.96 \%$ in the SHP465 MAS group.

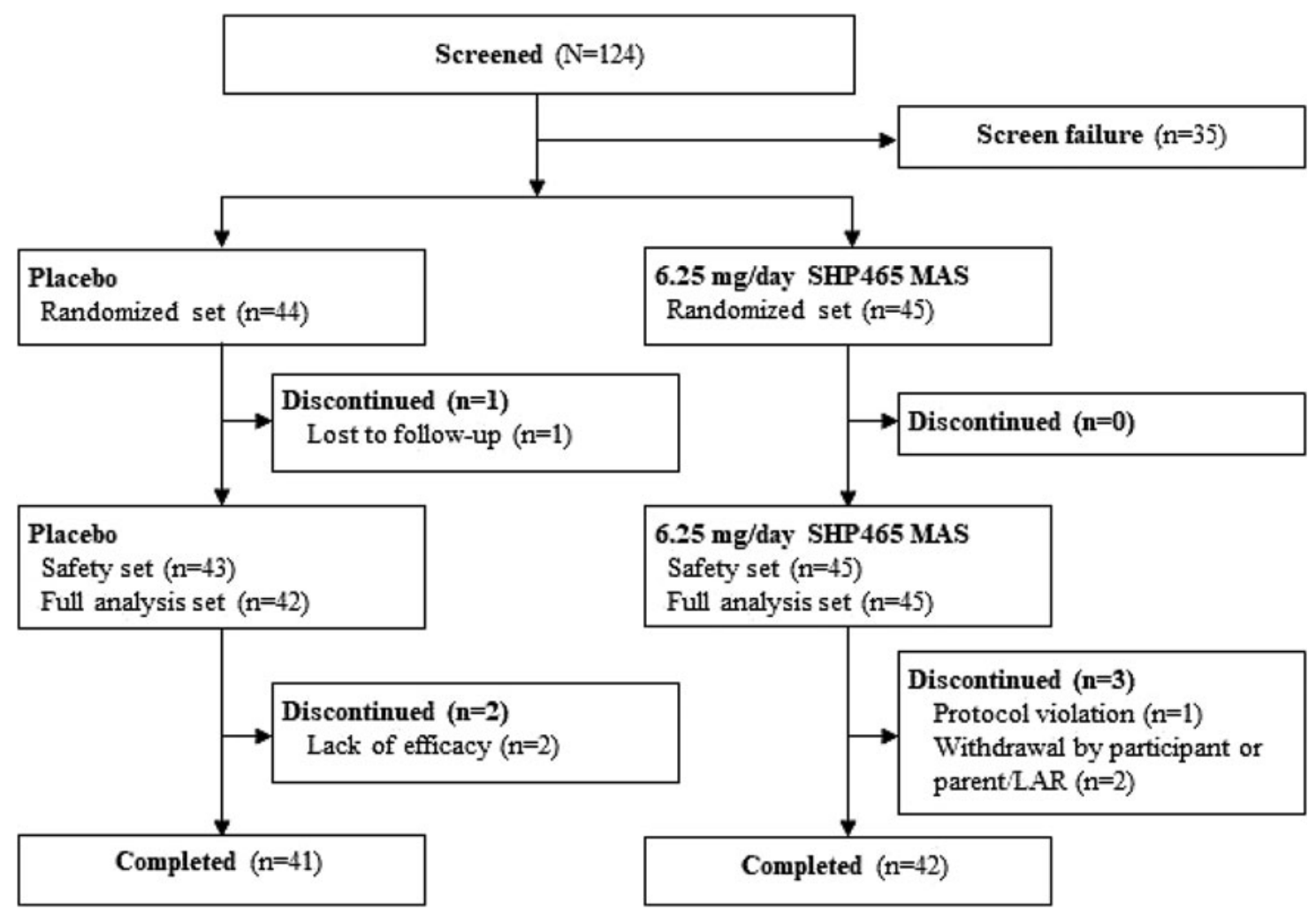

FIG. 1. Participant disposition. LAR, legally authorized representative; MAS, mixed amphetamine salts. 
Table 1. Baseline Demographics and Clinical Characteristics, Safety Set

\begin{tabular}{|c|c|c|}
\hline & $\begin{array}{l}\text { Placebo } \\
(\mathrm{n}=43)\end{array}$ & $\begin{array}{c}\text { SHP465 MAS } \\
\quad(\mathrm{n}=45)\end{array}$ \\
\hline Mean \pm SD age, years & $8.8 \pm 2.03$ & $8.8 \pm 2.20$ \\
\hline \multicolumn{3}{|l|}{ Age category, $n(\%)$} \\
\hline $6-12$ years & $22(51.2)$ & $22(48.9)$ \\
\hline $13-17$ years & $21(48.8)$ & $23(51.1)$ \\
\hline \multicolumn{3}{|l|}{ Sex, $n(\%)$} \\
\hline Male & $29(67.4)$ & $27(60.0)$ \\
\hline \multicolumn{3}{|l|}{ Race, $n(\%)$} \\
\hline White & $28(65.1)$ & $30(66.7)$ \\
\hline Black/African American & $10(23.3)$ & $11(24.4)$ \\
\hline $\begin{array}{l}\text { American Indian/Alaska } \\
\text { Native }\end{array}$ & $1(2.3)$ & 0 \\
\hline Other & $4(9.3)$ & $4(8.9)$ \\
\hline Mean \pm SD weight, $\mathrm{kg}$ & $36.1 \pm 17.26$ & $39.3 \pm 17.97$ \\
\hline Mean \pm SD BMI, $\mathrm{kg} / \mathrm{m}^{2}$ & $19.30 \pm 5.575$ & $20.17 \pm 5.007$ \\
\hline \multicolumn{3}{|c|}{ Mean \pm SD ADHD-RS-5-HV score ${ }^{\mathrm{a}}$} \\
\hline Total & $42.0 \pm 7.44$ & $39.9 \pm 9.17$ \\
\hline Hyperactivity/impulsivity & $20.6 \pm 4.41$ & $18.8 \pm 6.08$ \\
\hline Inattention & $21.3 \pm 4.31$ & $21.2 \pm 4.77$ \\
\hline $\begin{array}{l}\text { Mean } \pm \text { SD time since } \\
\text { ADHD diagnosis, years }\end{array}$ & $1.8 \pm 1.86$ & $1.8 \pm 2.27$ \\
\hline \multicolumn{3}{|l|}{ ADHD subtype, $n(\%)$} \\
\hline Inattentive & $2(4.7)$ & $10(22.2)$ \\
\hline Hyperactive/impulsive & $5(11.6)$ & $7(15.6)$ \\
\hline Combined & $36(83.7)$ & $28(62.2)$ \\
\hline \multicolumn{3}{|l|}{ CGI-S, $n(\%)^{\mathrm{b}}$} \\
\hline Moderately ill & $16(37.2)$ & $16(35.6)$ \\
\hline Markedly ill & $23(53.5)$ & $23(51.1)$ \\
\hline Severely ill & $2(4.7)$ & $6(13.3)$ \\
\hline Among the most extremely ill & $1(2.3)$ & 0 \\
\hline Missing & $1(2.3)$ & 0 \\
\hline
\end{tabular}

${ }^{\mathrm{a} B}$ Based on full analysis set (placebo, $n=42$; SHP465 MAS, $n=45$ ).

${ }^{\mathrm{b}}$ No participants were categorized as not assessed, normal (not at all ill), borderline mentally ill, or mildly ill.

ADHD, attention-deficit/hyperactivity disorder; ADHD-RS-5-HV, ADHDRating Scale, Fifth Edition, Child, Home Version; BMI, body mass index; CGI-S, Clinical Global Impressions-Severity; MAS, mixed amphetamine salts; SD, standard deviation.

\section{Efficacy}

Mean \pm SD ADHD-RS-5-HV total scores decreased from baseline to week 4 in both treatment groups (Fig. 2A). The least squares (LS) mean (95\% confidence interval [CI]) changes from baseline at week 4 were $-9.7(-13.2$ to -6.2$)$ and $-11.6(-15.0$ to -8.2) with placebo and SHP465 MAS, respectively. The LS mean $(95 \%$ CI) treatment difference between the SHP465 MAS and placebo groups (SHP465 MAS-placebo) for the change from baseline at week 4 was not statistically significant $(-1.9$ $[-6.8$ to 3.1$]$; test value $=-0.76$; degrees of freedom $=80.4$; $p=0.451 ; \mathrm{ES}, 0.17)$.

Mean \pm SD CGI-I scores by treatment week are presented in Figure 2B. LS mean (95\% CI) CGI-I scores at week 4 were 3.3 (3.0-3.6) and 3.2 (2.9-3.5) with placebo and SHP465 MAS, respectively. The LS mean (95\% CI) treatment difference between the SHP465 MAS and placebo groups for CGI-I score at week 4 was $-0.1 \quad(-0.5$ to 0.3$)$ (test value $=-0.53$; degrees of freedom $=75.5$; nominal $p=0.597$; ES, 0.12).

Consistent with findings for ADHD-RS-5-HV total scores, the LS mean $(95 \%$ CI) treatment difference between the SHP465 MAS
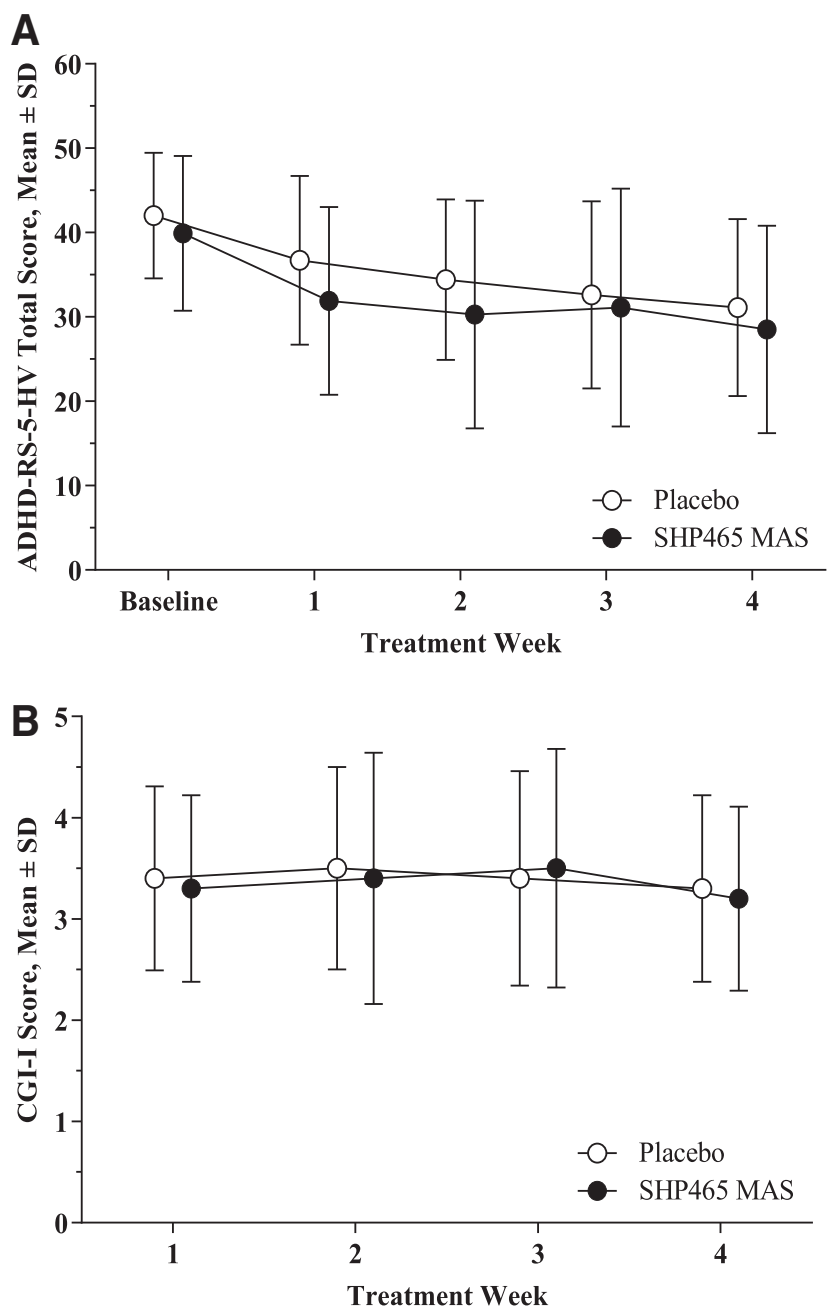

FIG. 2. Mean \pm SD ADHD-RS-5-HV total score (A) and CGI-I score (B) by visit and treatment group, full analysis set. ADHD, attention-deficit/hyperactivity disorder; ADHD-RS-5-HV, ADHDRating Scale, Fifth Edition, Child, Home Version; CGI-I, Clinical Global Impressions-Improvement; MAS, mixed amphetamine salts; $\mathrm{SD}$, standard deviation.

and placebo groups for the change from baseline to week 4 was not statistically significant for the ADHD-RS-5-HV hyperactivity/ impulsivity subscale $(-0.9$ [ -3.5 to 1.8$]$; test value $=-0.65$; degrees of freedom $=80.5$; nominal $p=0.516$; ES, 0.14$)$ or the inattention subscale $(-0.8[-3.4$ to 1.8$]$; test value $=-0.64$; degrees of freedom $=81.5$; nominal $p=0.526$; ES, 0.14). At the FoTA, $14.3 \%$ (6/42) of placebo participants and $17.8 \%(8 / 45)$ of SHP465 MAS participants were categorized as improved on the CGI-I. The LS mean (95\% CI) difference between the SHP465 MAS and placebo groups in the improved proportion of participants was not statistically significant (3.5 [ -17.8 to 24.6 ]; test value $=0.0245$; degrees of freedom $=1$; nominal $p=0.876$ ).

Exploratory analyses of changes in ADHD-RS-5-HV total score by participant age indicated that LS mean $(95 \% \mathrm{CI})$ changes from baseline at week 4 with placebo and SHP465 MAS, respectively, were -11.0 $(-16.8$ to -5.3$)$ and $-12.2(-18.0$ to -6.4$)$ in participants aged 6-8 years and $-8.0(-12.3$ to -3.7$)$ and $-11.0(-15.0$ to -7.1$)$ in participants aged 9-12 years. The LS mean $(95 \% \mathrm{CI})$ treatment differences between SHP465 MAS and placebo were -1.1 ( -9.4 to 7.1$)$ in participants aged $6-8$ years and -3.0 ( -8.9 to 2.8$)$ in participants aged $9-12$ years. 


\section{Safety and tolerability}

The overall percentage of participants reporting any TEAE was $16.3 \%$ (7/43) in the placebo group and $24.4 \%$ (11/45) in the SHP465 MAS group (Table 2). There were no serious TEAEs, severe TEAEs, or TEAEs leading to discontinuation or death reported. The most frequently reported TEAEs in both groups-

Table 2. Summary of Safety and Tolerability End Points, SafeTy Set

\begin{tabular}{|c|c|c|}
\hline & $\begin{array}{l}\text { Placebo } \\
(\mathrm{n}=43)\end{array}$ & $\begin{array}{l}\text { SHP465 MAS } \\
\quad(\mathrm{n}=45)\end{array}$ \\
\hline Any TEAE, $n(\%)$ & $7(16.3)$ & $11(24.4)$ \\
\hline Serious TEAE & 0 & 0 \\
\hline $\begin{array}{l}\text { TEAEs leading to dose } \\
\text { discontinuation }\end{array}$ & 0 & 0 \\
\hline Severe TEAEs & 0 & 0 \\
\hline Serious TEAEs leading to death & 0 & 0 \\
\hline \multicolumn{3}{|c|}{ Any TEAEs reported by $\geq 2$ participants, $n(\%)$} \\
\hline Headache & $3(7.0)$ & $2(4.4)$ \\
\hline Decreased appetite & $2(4.7)$ & $1(2.2)$ \\
\hline Diarrhea & $1(2.3)$ & $1(2.2)$ \\
\hline Medication error & $1(2.3)$ & $1(2.2)$ \\
\hline \multicolumn{3}{|c|}{ Vital signs, mean \pm SD change from baseline at FoTA } \\
\hline $\mathrm{SBP}, \mathrm{mmHg}$ & $-0.8 \pm 6.23$ & $1.8 \pm 6.52$ \\
\hline $\mathrm{DBP}, \mathrm{mmHg}$ & $0.3 \pm 6.61$ & $3.1 \pm 7.24$ \\
\hline Pulse, bpm & $-1.8 \pm 10.02$ & $-0.5 \pm 9.87$ \\
\hline \multicolumn{3}{|l|}{ Vital sign outliers, $n(\%)$} \\
\hline $\begin{array}{l}\text { SBP }>120 \mathrm{mmHg} \text { and increase } \\
>10 \mathrm{mmHg} \text { from baseline on } \\
\geq 2 \text { consecutive visits over } \\
\text { entire study }\end{array}$ & 0 & 0 \\
\hline $\begin{array}{l}\text { SBP }>120 \mathrm{mmHg} \text { and increase } \\
>10 \mathrm{mmHg} \text { from baseline at } \\
\text { FoTA }\end{array}$ & 0 & $1(2.2)$ \\
\hline $\begin{array}{l}\text { DBP }>80 \mathrm{mmHg} \text { and increase } \\
>10 \mathrm{mmHg} \text { from baseline on } \\
\geq 2 \text { consecutive visits over } \\
\text { entire study }\end{array}$ & 0 & 0 \\
\hline $\begin{array}{l}\text { DBP }>80 \mathrm{mmHg} \text { and increase } \\
>10 \mathrm{mmHg} \text { from baseline at } \\
\text { FoTA }\end{array}$ & 0 & $2(4.4)$ \\
\hline $\begin{array}{l}\text { Pulse } \geq 100 \mathrm{bpm} \text { and increase } \\
>15 \mathrm{bpm} \text { from baseline on } \geq 2 \\
\text { consecutive visits over entire } \\
\text { study }\end{array}$ & 0 & 0 \\
\hline $\begin{array}{l}\text { Pulse } \geq 100 \mathrm{bpm} \text { and increase } \\
>15 \mathrm{bpm} \text { from baseline at } \\
\text { FoTA }\end{array}$ & $1(2.3)$ & 0 \\
\hline \multicolumn{3}{|l|}{ Weight at FoTA } \\
\hline Mean \pm SD change at FoTA, $\mathrm{kg}$ & $0.5 \pm 0.77$ & $0.1 \pm 0.90$ \\
\hline Mean \pm SD $z$ score & $0.38 \pm 1.251$ & $0.70 \pm 1.420$ \\
\hline Median $z$ score & -0.04 & 0.55 \\
\hline $\begin{array}{l}\text { Weight decrease } \geq 7 \% \text { from } \\
\text { baseline, } n(\%)\end{array}$ & 0 & 0 \\
\hline \multicolumn{3}{|l|}{ BMI at FoTA } \\
\hline $\begin{array}{l}\text { Mean } \pm \text { SD change at FoTA } \\
\mathrm{kg} / \mathrm{m}^{2}\end{array}$ & $0.12 \pm 0.428$ & $-0.09 \pm 0.561$ \\
\hline Mean \pm SD $z$ score & $0.52 \pm 1.274$ & $0.85 \pm 1.080$ \\
\hline Median $z$ score & 0.31 & 0.76 \\
\hline
\end{tabular}

BMI, body mass index; bpm, beats per minute; DBP, diastolic blood pressure; FoTA, final on-treatment assessment; MAS, mixed amphetamine salts; SBP, systolic blood pressure; SD, standard deviation; TEAE, treatment-emergent adverse event. headache and decreased appetite-occurred more frequently with placebo than with SHP465 MAS (Table 2).

Mean reductions from baseline to FoTA in pulse were observed in the placebo and SHP465 MAS groups (Table 2). Mean decreases in SBP and increases in DBP from baseline to FoTA were observed in the placebo group, whereas increases in both SBP and DBP were observed in the SHP465 MAS group. Small percentages of participants in each treatment group met vital sign outlier criteria (Table 2). Mean increases from baseline to FoTA in weight were observed in both treatment groups (Table 2). For BMI, a mean increase from baseline to FoTA was observed in the placebo group, and a mean decrease was observed in the SHP465 MAS group (Table 2).

Mean \pm SD changes from baseline to FoTA in heart rate based on the ECG were $-0.61 \pm 9.433$ beats per minute (bpm) with placebo and $-1.12 \pm 11.711 \mathrm{bpm}$ with SHP465 MAS. Mean \pm SD changes from baseline at FoTA for the Frederica corrected QT interval (QTcF) were $-0.37 \pm 14.855 \mathrm{msec}$ with placebo and $-2.62 \pm 15.225 \mathrm{msec}$ with SHP465 MAS. No participants in either treatment group had QTcF intervals $\geq 500 \mathrm{msec}$.

On the PSQ and CSHQ, there were no apparent group differences at baseline or week 4 (Table 3).

On the C-SSRS, two participants in the SHP465 MAS group reported positive responses on the "wish to be dead" item. One participant responded positively at baseline before taking the first dose of SHP465 MAS. Another participant responded positively at week 1; this response was considered a nonserious psychiatric TEAE and was deemed by the investigator to not be related to SHP465 MAS. No positive responses for a lifetime history of suicide were reported; no suicide attempts were reported at baseline or during this study.

\section{Discussion}

The results of this double-blind, randomized, placebo-controlled study in children aged 6-12 years demonstrated that $6.25 \mathrm{mg}$ SHP465 MAS once daily (a dose that is one-half of the lowest approved dose of $12.5 \mathrm{mg}$ for adolescents and adults) were not superior to placebo in improving ADHD symptoms, as measured by ADHD-RS-5-HV total score reductions or more broadly by clinician ratings on the CGI. In addition, exploratory analyses based on participant age indicated that $6.25 \mathrm{mg}$ SHP465 MAS were not superior to placebo in participants aged 6-8 years or participants aged 9-12 years. The overall safety and tolerability profile of $6.25 \mathrm{mg}$ SHP465 MAS was similar to placebo in this study, with the TEAE types reported being consistent with the phase 3 study of $12.5 \mathrm{mg}$ and $25 \mathrm{mg}$ SHP465 MAS conducted in children and adolescents aged 6-17 years (Brams et al. 2018) and with other studies of amphetamine-based stimulants in pediatric populations (Biederman et al. 2002, 2007; Spencer et al. 2006; Findling et al. 2011; Stein et al. 2011). Taken together, these findings indicate that the 6.25 -mg dose of SHP465 MAS used in this study was generally well tolerated, but was subtherapeutic in this population of children aged 6-12 years.

In the previously published pivotal study of dose-optimized SHP465 MAS (12.5-25 mg) in children and adolescents aged 6-12 years, SHP465 MAS were statistically superior to placebo in reducing ADHD-RS-IV total score (ES, 0.80) and CGI-I scale score (ES, 0.65) after 4 weeks of treatment (Brams et al. 2018). However, in that study, only $24.2 \%$ (32/132) of all study participants (Brams et al. 2018) —and only 24.1\% (13/54) of participants aged 6-12 years (Brams M and Yu M; unpublished data) — were optimized to 
Table 3. Summary of Post Sleep Questionnaire and Children's Sleep Habits Questionnaire Scores at Baseline and Week 4, Safety Set

\begin{tabular}{|c|c|c|c|c|}
\hline & \multicolumn{2}{|c|}{ Placebo } & \multicolumn{2}{|c|}{ SHP465 MAS } \\
\hline & Baseline & Week 4 & Baseline & Week 4 \\
\hline \multicolumn{5}{|l|}{$\mathrm{PSQ}^{\mathrm{a}}$} \\
\hline Mean \pm SD minutes to fall asleep per night & $27.0 \pm 20.25$ & $19.3 \pm 16.13$ & $27.2 \pm 21.51$ & $21.0 \pm 14.35$ \\
\hline \multicolumn{5}{|l|}{ Woke up during the night } \\
\hline$n(\%)$ & $20(46.5)$ & $13(30.2)$ & $14(31.1)$ & $11(24.4)$ \\
\hline Mean \pm SD number of times ${ }^{b}$ & $1.4 \pm 0.50$ & $1.4 \pm 0.51$ & $1.5 \pm 0.76$ & $1.3 \pm 1.01$ \\
\hline \multicolumn{5}{|l|}{ Distribution of number of times, $n(\%)$} \\
\hline 0 & 0 & 0 & $1(2.2)$ & $1(2.2)$ \\
\hline 1 & $12(27.9)$ & $8(18.6)$ & $6(13.3)$ & $8(17.8)$ \\
\hline 2 & $8(18.6)$ & $5(11.6)$ & $6(13.3)$ & $1(2.2)$ \\
\hline 3 & 0 & 0 & $1(2.2)$ & 0 \\
\hline 4 & 0 & 0 & 0 & $1(2.2)$ \\
\hline Mean \pm SD minutes awake per night $\mathrm{b}^{\mathrm{b}, \mathrm{c}}$ & $12.4 \pm 8.41$ & $8.9 \pm 5.18$ & $8.0 \pm 7.63$ & $15.1 \pm 17.01$ \\
\hline \multicolumn{5}{|c|}{ Overall sleep quality during the past week, $n(\%)$} \\
\hline Very poor & $1(2.3)$ & 0 & 0 & 0 \\
\hline Poor & $4(9.3)$ & $3(7.0)$ & $6(13.3)$ & $6(13.3)$ \\
\hline Average & $15(34.9)$ & $12(27.9)$ & $16(35.6)$ & $12(26.7)$ \\
\hline Good & $15(34.9)$ & $14(32.6)$ & $16(35.6)$ & $17(37.8)$ \\
\hline Very good & $8(18.6)$ & $11(25.6)$ & $4(8.9)$ & $7(15.6)$ \\
\hline \multicolumn{5}{|l|}{ Past week was a typical week } \\
\hline No, $n(\%)$ & $4(9.3)$ & $4(9.3)$ & $6(13.3)$ & $6(13.3)$ \\
\hline \multicolumn{5}{|c|}{ Reason the past week was not typical, $n(\%)$} \\
\hline Vacation & $2(4.7)$ & 0 & $2(4.4)$ & 0 \\
\hline School break & $1(2.3)$ & $3(7.0)$ & $2(4.4)$ & $3(6.7)$ \\
\hline Was ill & 0 & 0 & 0 & $1(2.2)$ \\
\hline Other & $1(2.3)$ & $1(2.3)$ & $2(4.4)$ & $2(4.4)$ \\
\hline Mean \pm SD hours sleeping per night & $8.9 \pm 1.20$ & $9.1 \pm 1.34$ & $8.8 \pm 1.22$ & $8.9 \pm 1.16$ \\
\hline \multicolumn{5}{|l|}{ Overall sleep quality, $n(\%)$} \\
\hline Better than usual & 0 & $1(2.3)$ & $1(2.2)$ & $2(4.4)$ \\
\hline Same as usual & $6(14.0)$ & $4(9.3)$ & $7(15.6)$ & $7(15.6)$ \\
\hline Worse than usual & $2(4.7)$ & 0 & $1(2.2)$ & $2(4.4)$ \\
\hline \multicolumn{5}{|l|}{$\mathrm{CSHQ},{ }^{\mathrm{e}}$ mean $\pm \mathrm{SD}$} \\
\hline Total sleep disturbance score & $45.3 \pm 10.08$ & $42.7 \pm 9.36$ & $45.4 \pm 8.65$ & $42.8 \pm 9.17$ \\
\hline Bedtime resistance & $8.3 \pm 2.76$ & $7.3 \pm 1.84$ & $8.8 \pm 2.94$ & $8.3 \pm 2.49$ \\
\hline Sleep onset delay & $1.8 \pm 0.79$ & $1.5 \pm 0.75$ & $1.8 \pm 0.83$ & $1.5 \pm 0.78$ \\
\hline Sleep duration & $4.5 \pm 1.67$ & $4.2 \pm 1.51$ & $4.4 \pm 1.95$ & $4.0 \pm 1.72$ \\
\hline Sleep anxiety & $5.3 \pm 1.58$ & $5.0 \pm 1.65$ & $5.5 \pm 1.79$ & $5.2 \pm 1.70$ \\
\hline Night waking & $4.2 \pm 1.47$ & $4.1 \pm 1.49$ & $3.7 \pm 1.14$ & $3.7 \pm 1.25$ \\
\hline Parasomnias & $9.0 \pm 2.35$ & $8.7 \pm 2.73$ & $8.6 \pm 1.77$ & $8.2 \pm 1.88$ \\
\hline Disordered breathing & $3.5 \pm 0.86$ & $3.5 \pm 1.07$ & $3.4 \pm 0.71$ & $3.3 \pm 0.85$ \\
\hline Sleepiness & $11.5 \pm 3.19$ & $10.9 \pm 3.09$ & $12.0 \pm 3.39$ & $11.2 \pm 3.02$ \\
\hline
\end{tabular}

${ }^{\text {a }} n=43$ for placebo and $n=42$ for SHP465 MAS at baseline; $n=40$ for placebo and $n=42$ for SHP465 MAS at week 4 (based on average school/week nights).

${ }^{\mathrm{b}}$ Based on the total number of participants who woke during the night.

${ }^{c} n=12$ for placebo at week 4 .

${ }^{\mathrm{d}}$ Based on past week.

${ }^{\mathrm{e}} n=42$ for placebo and $n=45$ for SHP465 MAS at baseline; $n=41$ for placebo and $n=41$ for SHP465 MAS at week 4.

CSHQ, Children's Sleep Habits Questionnaire; MAS, mixed amphetamine salts; PSQ, Post Sleep Questionnaire; SD, standard deviation.

$12.5 \mathrm{mg}$ SHP465 MAS. When considered in light of previous findings, it is not surprising that $6.25 \mathrm{mg}$ SHP465 MAS once daily were found to be subtherapeutic in this study.

The treatment difference in the overall TEAE frequency (SHP465 MAS-placebo) in the current study was 8.1\% compared with $20.8 \%$ in children and adolescents treated with $12.5-25 \mathrm{mg}$ SHP465 MAS (Brams et al. 2018) and 15.7\%-31.9\% in adults treated with 12.5-75 mg SHP465 MAS (Spencer et al. 2008; Weisler et al. 2017; Frick et al. 2020). In addition, the two most frequently reported TEAEs (headache and decreased appetite) were reported more frequently with placebo than with SHP465 MAS.
This reinforces the value of controlled trials and emphasizes the effect that expectation bias may have on the frequency and type of adverse event reporting.

In the same way, the effects of SHP465 MAS on vital sign changes and weight were less pronounced in this study compared with the previous study in children and adolescents (Brams et al. 2018). In the current study, mean increases with SHP465 MAS in SBP (1.8 vs. -0.8 with placebo) and DBP (3.1 vs. $0.3 \mathrm{mmHg}$ with placebo) were observed at FoTA, and a mean decrease in pulse ( -0.5 vs. $-1.8 \mathrm{bpm}$ with placebo) was observed. In contrast, children and adolescents treated with $12.5-25 \mathrm{mg}$ SHP465 MAS tended 
to exhibit larger magnitude mean increases in SBP (3.8 vs. $2.1 \mathrm{mmHg}$ with placebo), DBP (4.0 vs. $0.5 \mathrm{mmHg}$ with placebo), and pulse (5.7 vs. $0.7 \mathrm{bpm}$ with placebo) (Brams et al. 2018).

As measured by modified versions of the PSQ and CSHQ, there were no apparent differences in sleep-related parameters at baseline and no consistent worsening of sleep associated with SHP465 treatment. These findings are consistent with those of previously published studies of SHP465 MAS in adults (Spencer et al. 2008; Frick et al. 2020), which reported no notable differences in sleep quality between SHP465 MAS and placebo based on Pittsburgh Sleep Quality Index total score. Although there were no reports of insomnia-related TEAEs in the current study, it should be noted that insomnia has been reported to be among the most frequently reported TEAEs in previously published studies of SHP465 MAS in adults (Spencer et al. 2008; Weisler et al. 2017; Frick et al. 2020) and in children and adolescents (Brams et al. 2018).

These data should be considered in light of certain limitations. First, clinical trial study designs can have limited generalizability based on age and sex distributions of the study population. However, the current study enrolled a more homogenous study population, with a relatively narrow age range and a greater percentage of girls than is typical of clinical studies of pediatric ADHD. Second, the efficacy data are based on the population mean. Therefore, individual participants may have benefitted from the low dose of SHP465 MAS used in this study. Third, SHP465 MAS delivers amphetamine over time using three beads with three distinct release profiles (Ermer et al. 2007). As such, it is possible that efficacy versus placebo was not observed with $6.25 \mathrm{mg}$ SHP465 MAS because a critical plasma amphetamine level was not attained. Fourth, the participants included in this study had different histories of stimulant exposure, with many reporting no prior stimulant use.

At this time, post hoc analyses of SHP465 MAS treatment responses based on stimulant treatment history for participants in this study are not available. Therefore, it is not known if prior exposure to a stimulant influenced responses to this low dose of SHP465 MAS. It is also not known whether participant weight or BMI influenced SHP465 MAS treatment responses. Fifth, measures of inter-rater reliability and consistency for the primary outcome measure are not available, so it is not known if variability in ADHD symptom ratings could have contributed to the lack of statistical differences between SHP465 MAS and placebo. However, the lack of efficacy in this study is thought to be primarily due to the low SHP465 MAS dose administered rather than rater qualifications. It should also be noted that although the double-blind design of this study did not reduce the variation among raters, it did minimize subjective bias. Finally, it is unknown if an intermediate dose between 6.25 and $12.5 \mathrm{mg}$ would have demonstrated efficacy versus placebo. Given the known efficacy of MAS formulations in the treatment of children and adolescents with ADHD (Swanson et al. 1998; Pliszka et al. 2000; Biederman et al. 2002; McCracken et al. 2003; Spencer et al. 2006), additional studies that examine broader dose ranges should be considered.

\section{Conclusions}

In children aged 6-12 years diagnosed with ADHD, 6.25 mg SHP465 MAS once daily (one-half of the lowest FDA-approved dose of SHP465 MAS in adolescents and adults) were not statistically superior to placebo in reducing ADHD symptoms, as measured by ADHD-RS-5-HV total score change, or in producing global disease improvement, as measured by CGI-I score. Taken together, these findings indicate that $6.25 \mathrm{mg}$ SHP465 MAS were subtherapeutic in this study population. The overall tolerability profile of $6.25 \mathrm{mg}$ of SHP465 MAS was similar to placebo in this study, with the same types of TEAEs being reported that have been reported after treatment with 12.5 and $25 \mathrm{mg}$ SHP465 MAS in children and adolescents aged 6-17 years (Brams et al. 2018).

\section{Clinical Significance}

SHP465 MAS (SHP465 MAS) extended-release is a once-daily psychostimulant approved by the U.S. FDA for the treatment of ADHD in individuals aged $\geq 13$ years. In a previous report, the efficacy of dose-optimized SHP465 MAS (12.5-25 mg once daily) versus placebo was demonstrated in children and adolescents aged 6-17 years. The current study was conducted to examine the efficacy, safety, and tolerability of $6.25 \mathrm{mg}$ SHP465 MAS—a dose that is one-half of the lowest approved dose in adolescents and adultsin children aged 6-12 years. The data demonstrate that $6.25 \mathrm{mg}$ SHP465 MAS were generally well tolerated, but were not efficacious versus placebo in reducing ADHD symptoms. The data from this study provide important information to clinicians about the efficacy and safety of SHP465 MAS in 6- to 12-year-old children at a dose that is one-half of the lowest dose currently approved for use in adolescents and adults.

\section{Acknowledgments}

Under the direction of the authors, Shelly Lim, PhD, and Craig Slawecki, PhD, employees of ICON plc (North Wales, PA), provided writing assistance for this article.

\section{Disclosures}

G.M. has served as a speaker for Allergan, Alkermes, Lundbeck, Neos, Otsuka, Shire, Sunovion, and Takeda; been a consultant for Alkermes, Allergan, Intracellular, Lundbeck, Otsuka, Perdue, Rhodes, Sage, Shire, Sunovion, Supernus, and Takeda; and received research funds from Akili, Alkermes, Allergan, Axsome, Boehringer, Janssen, Medgenics, NLS-1 Pharma AG, Sage, Shire, Sunovion, Supernus, and Takeda. V.A. has received honoraria from Ironshore, Neos, Rho, and Shire; has served as a consultant for Ironshore; has served on the speaker's bureau for Takeda; and holds Supernus stock and/or stock options. B.Y. and M.Y. are employees of Shire, a member of the Takeda group of companies, and hold Takeda stock. B.R. was an employee of Shire, a member of the Takeda group of companies, at the time this research was conducted and holds Takeda stock; she is currently employed by Yumanity Therapeutics, Inc., (Cambridge, MA).

\section{References}

American Psychiatric Association. Diagnostic and Statistical Manual of Mental Disorders, 5th ed. Washington, DC: American Psychiatric Association; 2013.

Biederman J, Krishnan S, Zhang Y, McGough JJ, Findling RL: Efficacy and tolerability of lisdexamfetamine dimesylate (NRP-104) in children with attention-deficit/hyperactivity disorder: A phase III, multicenter, randomized, double-blind, forced-dose, parallelgroup study. Clin Ther 29:450-463, 2007.

Biederman J, Lopez FA, Boellner SW, Chandler MC: A randomized, double-blind, placebo-controlled, parallel-group study of SLI381 (Adderall XR) in children with attention-deficit/hyperactivity disorder. Pediatrics 110:258-266, 2002. 
Brams M, Childress AC, Greenbaum M, Yu M, Yan B, Jaffee M, Robertson B: SHP465 mixed amphetamine salts in the treatment of attention-deficit/hyperactivity disorder in children and adolescents: Results of a randomized, double-blind placebo-controlled study. J Child Adolesc Psychopharmacol 28:19-28, 2018.

Canafax DM, Bhanegaonkar A, Bharmal M, Calloway M: Validation of the post sleep questionnaire for assessing subjects with restless legs syndrome: Results from two double-blind, multicenter, placebo-controlled clinical trials. BMC Neurol 11:48, 2011.

DuPaul GJ, Power TJ, Anastopoulos AD, Reid R: Introduction to the ADHD rating scales. In: ADHD Rating Scale-5 for Children and Adolescents: Checklists, Norms, and Clinical Interpretation. New York, Guilford Publications, 2016, pp. 1-6.

Ermer JC, Shojaei A, Pennick M, Anderson CS, Silverberg A, Youcha SH: Bioavailability of triple-bead mixed amphetamine salts compared with a dose-augmentation strategy of mixed amphetamine salts extended release plus mixed amphetamine salts immediate release. Curr Med Res Opin 23:1067-1075, 2007.

Findling RL, Childress AC, Cutler AJ, Gasior M, Hamdani M, FerreiraCornwell MC, Squires L: Efficacy and safety of lisdexamfetamine dimesylate in adolescents with attention-deficit/hyperactivity disorder. J Am Acad Child Adolesc Psychiatry 50:395-405, 2011.

Frick G, Yan B, Adler LA: Triple-bead mixed amphetamine salts (SHP465) in adults with ADHD: Results of a phase 3, double-blind, randomized, forced-dose trial. J Atten Disord 24:402-413, 2020.

Guy W: Clinical Global Impressions. Rockville (Maryland), US Department of Health, Education, and Welfare; Public Health Service; Alcohol, Drug Abuse and Mental Health Administration, NIMH Psychopharmacology Research Branch, 1976.

McCracken JT, Biederman J, Greenhill LL, Swanson JM, McGough JJ, Spencer TJ, Posner K, Wigal S, Pataki C, Zhang Y, Tulloch S: Analog classroom assessment of a once-daily mixed amphetamine formulation, SLI381 (Adderall XR), in children with ADHD. J Am Acad Child Adolesc Psychiatry 42:673-683, 2003.

Mydayis $^{\circledR}$ (Mixed Salts of a Single-Entity Amphetamine Product): Full Prescribing Information. Lexington (Massachusetts), Shire US, Inc., 2019.

Owens JA, Spirito A, McGuinn M: The Children's Sleep Habits Questionnaire (CSHQ): Psychometric properties of a survey instrument for school-aged children. Sleep 23:1043-1051, 2000.

Pliszka SR, Browne RG, Olvera RL, Wynne SK: A double-blind, placebo-controlled study of Adderall and methylphenidate in the treatment of attention-deficit/hyperactivity disorder. J Am Acad Child Adolesc Psychiatry 39:619-626, 2000.

Posner K, Brown GK, Stanley B, Brent DA, Yershova KV, Oquendo MA, Currier GW, Melvin GA, Greenhill L, Shen S, Mann JJ: The Columbia-Suicide Severity Rating Scale: Initial validity and internal consistency findings from three multisite studies with adolescents and adults. Am J Psychiatry 168:1266-1277, 2011.

Spencer TJ, Adler LA, Weisler RH, Youcha SH: Triple-bead mixed amphetamine salts (SPD465), a novel, enhanced extended-release amphetamine formulation for the treatment of adults with ADHD: A randomized, double-blind, multicenter, placebo-controlled study. J Clin Psychiatry 69:1437-1448, 2008.

Spencer TJ, Wilens TE, Biederman J, Weisler RH, Read SC, Pratt R: Efficacy and safety of mixed amphetamine salts extended release (Adderall XR) in the management of attention-deficit/hyperactivity disorder in adolescent patients: A 4-week, randomized, doubleblind, placebo-controlled, parallel-group study. Clin Ther 28:266279, 2006.

Stein MA, Waldman ID, Charney E, Aryal S, Sable C, Gruber R, Newcorn JH: Dose effects and comparative effectiveness of extended release dexmethylphenidate and mixed amphetamine salts. J Child Adolesc Psychopharmacol 21:581-588, 2011.

Swanson J, Wigal S, Greenhill L, Browne R, Waslick B, Lerner M, Williams L, Flynn D, Agler D, Crowley KL, Fineberg E, Regino R, Baren M, Cantwell D: Objective and subjective measures of the pharmacodynamic effects of Adderall in the treatment of children with ADHD in a controlled laboratory classroom setting. Psychopharmacol Bull 34:55-60, 1998.

United States Food and Drug Administration: Guidance for industry: How to comply with the Pediatric Research Equity Act. US Food and Drug Administration, Center for Drug Evaluation and Research (CDER). Available at: https://fda.gov/downloads/Drugs/ DevelopmentApprovalProcess/DevelopmentResources/UCM077855 .pdf (accessed March 29, 2019).

Weisler RH, Greenbaum M, Arnold V, Yu M, Yan B, Jaffee M, Robertson B: Efficacy and safety of SHP465 mixed amphetamine salts in the treatment of attention-deficit/hyperactivity disorder in adults: Results of a randomized, double-blind, placebo-controlled, forced-dose clinical study. CNS Drugs 31:685-697, 2017.

Wigal S, Lopez F, Frick G, Yan B, Robertson B, Madhoo M: A randomized, double-blind, 3-way crossover, analog classroom study of SHP465 mixed amphetamine salts extended-release in adolescents with ADHD. Postgrad Med 131:212-224, 2019.

Wigal T, Brams M, Frick G, Yan B, Madhoo M: A randomized, double-blind study of SHP465 mixed amphetamine salts extendedrelease in adults with ADHD using a simulated adult workplace design. Postgrad Med 130:481-493, 2018 a.

Wigal T, Childress A, Frick G, Yan B, Wigal S, Madhoo M: Effects of SHP465 mixed amphetamine salts in adults with ADHD in a simulated adult workplace environment. Postgrad Med 130:111-121, 2018 b.

Address correspondence to: Greg Mattingly, MD

Midwest Research Group

4801 Weldon Spring Parkway, Suite 300

St. Charles, MO 63304

USA

E-mail: greg@mattingly.com 